\title{
Comprehensive Evaluation of the Importance of Ecological Land in Arid Hilly Cities in Northwest China: A Case Study of the Core Urban Area of Lanzhou
}

\author{
Yiping Liu ${ }^{1}$, Chengpeng Lu ${ }^{1,2, *} \mathbb{C}$, Jinhuang Mao ${ }^{1,2}$, Jiaxing Pang ${ }^{3}\left(\mathbb{D}\right.$, Zhiliang Liu ${ }^{1,2}$ and Muchen Hou ${ }^{1,2}$ \\ 1 Institute of County Economic Development \& Rural Revitalization Strategy, Lanzhou University, \\ Lanzhou 730000, China; liuyiping@lzu.edu.cn (Y.L.); maojh@lzu.edu.cn (J.M.); zhlliu19@lzu.edu.cn (Z.L.); \\ houmch20@lzu.edu.cn (M.H.) \\ 2 School of Economics, Lanzhou University, Lanzhou 730000, China \\ 3 College of Earth and Environment Sciences, Lanzhou University, Lanzhou 730000, China; pangjx@lzu.edu.cn \\ * Correspondence: lcp@lzu.edu.cn
}

Citation: Liu, Y.; Lu, C.; Mao, J.;

Pang, J.; Liu, Z.; Hou, M.

Comprehensive Evaluation of the Importance of Ecological Land in Arid Hilly Cities in Northwest China: A Case Study of the Core Urban Area of Lanzhou. Land 2021, 10, 942. https://doi.org/10.3390/land10090942

Received: 14 August 2021

Accepted: 4 September 2021

Published: 7 September 2021

Publisher's Note: MDPI stays neutral with regard to jurisdictional claims in published maps and institutional affiliations.

Copyright: (c) 2021 by the authors. Licensee MDPI, Basel, Switzerland. This article is an open access article distributed under the terms and conditions of the Creative Commons Attribution (CC BY) license (https:// creativecommons.org/licenses/by/ $4.0 /)$.

\begin{abstract}
Cities in hilly arid areas of northwest China have generally experienced a low level of economic development; they also have unique natural characteristics such as climate, soil, terrain, environment, and surface cover. High quality ecological lands are those that provide humans and the environment with relatively high levels of ecological services including soil, water, and air purification, adsorbing pollutants, or providing water or nutrients needed by plants. In this study, ecological lands were classified as woodland, grassland, water area, and bare land. The present study constructed an ecological land model designed to evaluate the importance of such land from the perspective of ecological service function and ecological demand intensity. Results revealed that: (1) This model can help researchers to better analyze the structure and spatial characteristics of ecological land in cities and also meet the needs of ecological protection and urban management in highly urbanized areas. (2) In terms of ecological service function and ecological demand intensity, the most important ecological land is mostly distributed in densely populated and urbanized areas, and the spread of urbanization is conducive to the improvement of land ecological value for the arid hilly area of northwest China. (3) Among all types of ecological land, the water area had the highest ecological value in the study area, while the grassland had the most potential for improvement, as careful planning and use can allow grassland to function as an ecological barrier while providing good, aesthetically pleasing space for leisure activities for the general public. (4) Qilihe and Xigu districts have more generally important graded areas of forest, grassland, and bare land, although the current ecological value of these lands is limited, though they have great potential for ecological improvement.
\end{abstract}

Keywords: ecological land; ecological function; ecological demand; comprehensive evaluation; northwest China; Lanzhou city

\section{Introduction}

With the development of China's economy, society expects businesses and governments to maintain a high-quality environment. People's demand for a clean and ecologically stable living environment is growing [1]. The protection of important ecological land is an urgent task in support of the sustainable development of urban and rural areas in China, while identification and evaluation can effectively identify and screen ecological land by giving it a value, which is an important starting point for the construction of an ecologically sound civilization. Ecological land can be defined as land that provides humans, plants, and animals with environmental services including soil, water, and air purification or the mitigation of pollution, as well as providing natural land for grazing, recreation, or other needs [2]. For example, as ecological land, natural wetlands and grasslands can 
provide greater amounts of ecological services for humans than urbanized lands with little green space.

The identification of an ecological source is not only related to the formulation of a land use strategy and a choice of urban development path, but is also the basis for the establishment of an urban and rural ecological security pattern. It is of great significance to the play of regional ecological benefits and the coordination of the relationship between regional ecological protection and economic development. Originally, identification of ecological land was relatively coarse; for example, nature reserves or habitats of key species were often directly selected as the source of an ecological security pattern in scientific research and practice [3,4]. However, the designation of nature reserves ignores the specific conditions and characteristics of the environment, while the habitats of key species are limited by the availability and accuracy of species observation data. To avoid these shortcomings, scholars began to try to establish an index system from multiple perspectives that could be used to evaluate the importance of ecological patches, and regard the natural ecological attributes of these patches as the core of ecological land designation. The attributes of ecological patches, such as land cover type, patch area and shape, biodiversity maintenance, ecological sensitivity, and soil and water conservation, have become common indicators for the construction of systems designed to evaluate the importance of ecological land [5,6], and some studies have also included the structural importance of ecological patches in the evaluation framework [7]. These studies have greatly improved the scientific basis of ecological source identification. However, the importance of ecological land with the same natural attributes still varies by location [8]. With the acceleration of the process of urbanization in China, a large amount of ecological land in cities has been replaced by urbanized land, which has led to a scarcity [9]. The ecological land located in an urbanized area can beautify the environment, improve the local microclimate, shield residents from noise, provide convenient and comfortable resting places for human beings, help urban residents free themselves from the shackles of a reinforced concrete jungle, and help people relax in a natural environment [10-12]. This has an important value that ecological land on the periphery of a city cannot replace. Relatively intensive activities of residents occur in areas with ecological land, which has a relatively high service efficiency and visit rate [13]. In view of this, in recent years the evaluation of the importance of ecological land has been developing continuously. In addition to the natural service function provided by ecological patches, some studies have also included the need of human society for ecological service in its evaluation systems. The goal is to comprehensively delineate the ecological land that plays an important role in urban development from the dual perspectives of nature and society [14-16]. Doing so improves the methods of identifying important ecological sources in cities and strengthens the systematic process involved in the evaluation system. However, few such studies have been conducted in China, and this small number of studies is mainly oriented to the cities of eastern China [15,16], ignoring the adaptability of arid inland cities in northwest China. The climate and soil conditions, land cover, ecological status, level of economic development, and urban spatial layout of arid hilly areas in northwest China have unique characteristics. Therefore, it is necessary to adjust the index selection, weight distribution, and calculation method according to local conditions in the process of evaluating the importance of ecological land. At the same time, China has put forward the strategy of providing for ecological protection and producing high-quality development in the Yellow River Basin $[17,18]$. It is of practical significance to evaluate and study the importance of ecological land use for the arid inland cities along the upper reaches of the Yellow River in support of the ecologically sound management and economic development of the whole basin. In this context, this paper hopes to establish an improved evaluation model, which will help to identify and evaluate the importance of ecological land in arid and hilly areas in northwest China, and fill the gap in related fields of study. Moreover, this paper chooses Lanzhou as a case study considering that Lanzhou is the only provincial capital city in China where the Yellow River runs through the city and also serves as an important 
node of the Yellow River Basin and "one Belt and Road" initiative. For a long time, due to the dual influence of natural conditions and human activities, the ecological land in Lanzhou has been occupied and many habitats have been divided, which has greatly affected the urban environmental quality [19]. This paper expects to lay a foundation for ecological protection and high-quality development in Lanzhou through the identification of important ecological sources in its core urban area.

In light of the above discussion, this paper uses an improved model to evaluate the importance of ecological land in the core urban area of Lanzhou with specific attention to natural ecology and human needs. The purpose of this research is mainly twofold: (1) to construct a significant evaluation system for ecological land in the northwest arid hilly area, via the study's methodology; (2) to explore the structure and spatial distribution characteristics of ecological land in the core area of Lanzhou in a practical sense, to reveal the development characteristics of urban ecological land in the arid hilly region of northwest China, and to provide some guidance for the long-term development of Lanzhou.

\section{Materials and Methods}

\subsection{Overview of the Study Area and Data Sources}

Lanzhou, located at the geometric center of China, is an important central city, industrial base, transportation hub, and core node city of the Silk Road Economic Belt in northwest China. Lanzhou has jurisdiction over three counties (Yongdeng, Yuzhong, and Gaolan), five districts (Chengguan, Qilihe, Anning, Xigu, and Honggu), and three national development zones, with a total area of about $13,090 \mathrm{~km}^{2}$. In the fourth edition of the master plan for urban Lanzhou, the urban spatial structure was described as "one river, two banks, three centers and seven groups", in which the "three centers" were composed of the Chengguan, Anning-Qilihe, and Xigu central areas, used here as the study area, covering about $1046 \mathrm{~km}^{2}$ (Figure 1).

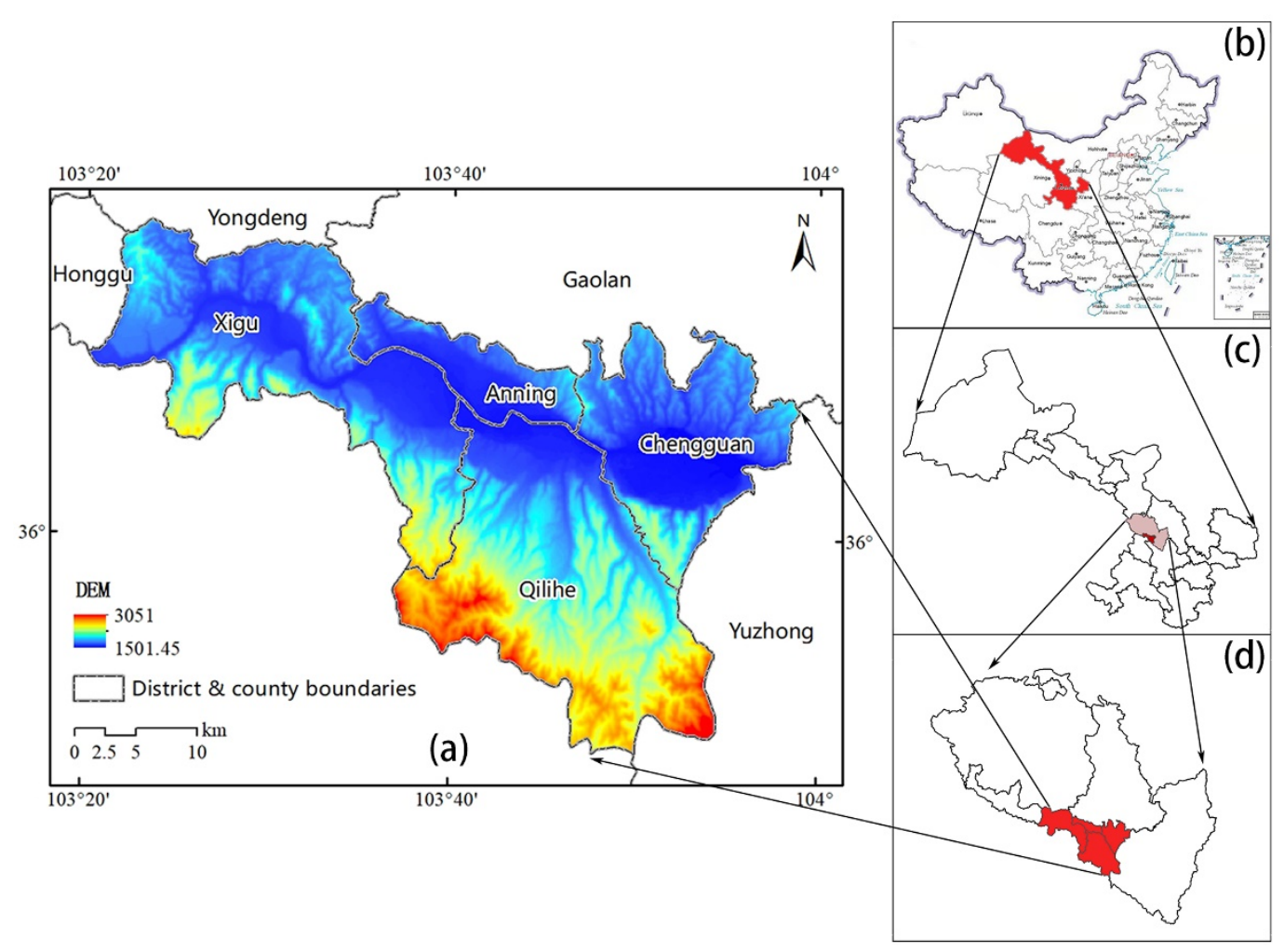

Figure 1. (a) Geographic location of the study area showing the elevations of Chengguan, Anning-Qilihe, and Xigu central areas. Inset maps show (b) the location of Gansu Province within China; (c) the location of Lanzhou within Gansu Province; (d) the locations of these central areas within Lanzhou. 
The data used in this study included Landsat 8 operational land imager thermal infrared sensor remote sensing images with a resolution of $30 \mathrm{~m}$ acquired in 2020 as land use source data (strip number 131; line number 35), and ENVI software was used to interpret the images. Based on the current land use classification (GB/T 21010-2017), the interpretation results were divided into six land use types: cultivated land, woodland, grassland, water area, construction land, and bare land. In this study, woodland, grassland, water area, and bare land were selected as four types of ecological land in the city according to the definition of ecological land in previous studies [2,20]. Finally, the spatial distribution data of ecological land in the core urban area of Lanzhou were obtained by delineating this in the ArcGIS software (EGIS, Redlands, CA, USA). Digital elevation model data came from BIGEMAP downloader with a resolution of $15 \mathrm{~m} \times 15 \mathrm{~m}$. The normalized difference vegetation index (NDVI) data were extracted from ENVI software based on remote sensing images; then fractional vegetation cover was calculated by the significant linear relationship between NDVI and vegetation cover [21,22]. The remote sensing images were acquired on 26 July 2020, during which the vegetation coverage was relatively good and could reflect the vegetation situation of Lanzhou in an ideal way. Nighttime light data was based on the 2020 global nighttime light data set obtained from the National Polar-orbiting partnership-visible infrared imaging radiometer suite satellite from the official website of the U.S. National Oceanic and Atmospheric Administration, which has higher precision than previous U.S. Defense Meteorological Satellite Program Operational Linescan System light data; soil erosion data were obtained from the Harmonized World Soil Database.

\subsection{Methodology Framework}

Previous studies have shown that the important ecological land in a city not only should help to maintain the normal operation of the natural ecosystem but should also provide green space for the leisure and entertainment activities of human society $[15,16]$. Therefore, this study evaluated the importance of ecological land in the core area of urban Lanzhou from the two aspects of ecological service function and ecological demand. When evaluating the ecological function, indicators should be selected according to regional characteristics. For Lanzhou, drought and water shortage, sparse vegetation and rugged terrain are its main natural characteristics [23]. Therefore, maintenance of biodiversity, soil conservation, and water conservation have become important factors affecting the ecological development level of Lanzhou. This paper also constructs the ecological function evaluation system based on these three aspects. In terms of social demand, the intensity of the demand of urban residents for ecological land is often related to the spatial location of this ecological land, the number of services covered, and other factors; therefore, the spatial differences of human activity factors were mainly considered. In conclusion, the importance index $(E I)$ of normalized ecological function and normalized ecological demand index $(D I)$ were mainly introduced to characterize the comprehensive importance index $(P I)$ of ecological land:

$$
P I_{i}=E I_{i}+D I_{i}
$$

where $P I_{i}$ is the comprehensive importance index of ecological land, $E I_{i}$ is the normalized value of the importance index of ecological function, and $D I_{i}$ is the normalized value of the ecological demand index. After calculating all the importance indicators, the natural breakpoint classification method was used to divide the final evaluation results into five levels: most important, very important, important, generally important, and unimportant. Note that an italics font is used for these five levels of importance throughout the paper to help the reader realize which specific category is being discussed at any point.

The specific analytical methods used to find the ecological function importance index and ecological demand index follow. 


\subsection{Ecological Function Importance Assessment}

\subsubsection{Biodiversity Maintenance Function}

Different land use types have different functions in maintaining biodiversity. According to the biodiversity service equivalent formulated by Xie et al. [5] and referring to relevant research on the correction of a service value coefficient per unit area [24], the basic biodiversity service equivalent of farmland, woodland, grassland, water area, and bare land was determined to be $2.09,9.59,3.21,7.32$, and 1, respectively. In addition, previous studies have shown that variations in vegetation coverage will cause significant changes in the value of ecological services within a certain land use type [16,25-27]. Therefore, this paper also used the normalized vegetation index (NDVI) as a correction factor to correct the basic equivalent value; NDVI reflects the biodiversity maintenance function of ecological land:

$$
E V=\frac{N D V I_{i}}{N D V I_{t}} \times E V_{t}
$$

where $E V$ is the modified biodiversity service equivalent corresponding to grid $i, E V_{t}$ is the basic biodiversity service equivalent of land use type $t, N D V I_{i}$ is the normalized difference vegetation indices corresponding to grid $i$, and $N D V I_{t}$ is the average NDVI of ecological land type $t$.

\subsubsection{Soil Conservation Function}

The revised universal soil loss equation (RUSLE) has been widely used in the quantitative evaluation of the soil conservation function [28-33]. In this paper, the RUSLE was used to calculate the difference between potential and actual soil erosion to determine the soil conservation capacity of each land type. According to RUSLE, potential soil loss $\left(A_{0}\right)$ and actual soil erosion $(A)$ are mainly controlled by a rainfall erosion factor $(R)$, soil Erosivity Factor $(K)$, slope length and slope factor $(L S)$, vegetation coverage factor $(C)$, and engineering measures factor $(P)$. The calculation formula of soil conservation $\left(A_{1}\right)$ is as follows:

$$
A_{1}=A_{0}-A=R \times K \times L S-R \times K \times L S \times C \times P=R \times K \times L S \times(1-C \times P),
$$

where $R, K, L S$, and $C$ can be calculated by the RUSLE and the grid calculator function of ArcGIS [26-29]. In addition, combined with previous studies, different $p$-values were given to the various ecological land types in the core urban area of Lanzhou: 1 for woodland, grassland, and bare land, 0 for water area.

\subsubsection{Water Conservation Function}

The water conservation function was evaluated from three dimensions: distance from water area, slope, and fractional vegetation cover. Generally speaking, the closer to a water source, the higher the vegetation coverage, and the smoother the slopes, the stronger the water conservation function $[15,16,34]$, and zones with suitable human settlements are also primarily distributed in regions with a moderate relief degree of the land surface, adequate vegetation cover and abundant water resources [35]. At the same time, due to the differences in the role of these three dimensions in water conservation in the core urban area of Lanzhou, the weights of distance to water, slope, and vegetation coverage were determined through a combination of expert scoring and the Analytic Hierarchy Process (AHP). The specific data and importance grades are shown in Table 1. The classification and weight of these indicators are only for ecological land, not including non-ecological land such as construction land. In fact, the evaluation parameters of construction land will be different from ecological land, such as slower slope and lower requirements for vegetation coverage. Moreover, the related factors used in the evaluation of the water conservation function were mainly determined according to the climatic conditions, geomorphic types, land cover, and ecological status of Lanzhou, which can represent the characteristics of cities in arid hilly areas of northwest China to a certain extent. 
Table 1. Evaluation system for the function of water conservation.

\begin{tabular}{cccccc}
\hline Evaluation Factors & Distance from Water Area $\mathbf{( k m )}$ & Slope (\%) & FVC (\%) & \multirow{2}{*}{ Importance } \\
\cline { 1 - 4 } Weight & $\mathbf{0 . 3 5}$ & $\mathbf{0 . 1 8}$ & $\mathbf{0 . 4 7}$ & Value \\
\hline & $0-0.5$ & $<5$ & $0.5-1$ & Most important \\
Classification & $0.5-1$ & $5-10$ & $0.4-0.5$ & Very important & 4 \\
& $1-1.5$ & $10-15$ & $0.3-0.4$ & Important & 3 \\
& $1.5-2$ & $15-20$ & $0.2-0.3$ & Generally important & 2 \\
& $>2$ & $>20$ & $0-0.2$ & Unimportant \\
\hline
\end{tabular}

Note: FVC, Fractional Vegetation Cover.

\subsection{Assessment of Ecological Demand}

Previous studies have shown that evaluation of the importance of ecological land not only needs to involve analysis of the land's own natural ecological functions but also needs to consider the degree of demand in a city $[8,9,24]$. In general, the closer ecological land is to a residential area and the more people it serves, the higher the degree of demand will exist for that land. Therefore, the intensity of the demand of urban residents for ecological land is often related to the spatial location of that land, the number of people covered by its services, and other factors [15]. Nighttime light intensity has been proven to be a good reflection of the level of human activity such as regional population density and resource consumption, and provides a visual representation of the intensity of human activity that can be represented in a geographical spatial distribution [36,37]. In view of this, the present study used the nighttime light intensity to characterize the population density of different areas in the core urban area of Lanzhou. Then, combined with the traffic conditions and the specific travel situation for residents in Lanzhou, the different demand radii of ecological land for urban residents on working days and holidays were set based on the standard of $3 \mathrm{~km}$ and $10 \mathrm{~km}$, respectively. Finally, the kernel density estimation of ArcGIS was used to obtain the social demand intensity of ecological land under different demand radii. In addition, previous studies have pointed out that ecological land and water areas with good vegetation cover are often more attractive than other areas [13,15], so the normalized difference vegetation index (NDVI) and normalized difference water index (NDWI) should also be included in the calculation of ecological demand. In conclusion, based on the nighttime light intensity and the characteristics of ecological land, this paper constructed an ecological demand index, NI, of ecological land in the core urban area of Lanzhou

$$
N I=\frac{0.5 P D_{i}^{1}+0.5 P D_{i}^{2}}{E D_{i}} \times\left(N D V I_{i}+N D W I_{i}\right),
$$

where NI is the ecological demand index of grid $i ; P D_{i}^{1}$ and $P D_{i}^{2}$ are the social demand intensities of working days and holidays corresponding to grid $i$, respectively, i.e., the kernel density values of nighttime light intensity under different demand radii; $E D_{i}$ is the spatial distance between grid $i$ and a densely populated area, and $N D V I_{i}$ and $N D W I_{i}$ are the normalized difference vegetation and water indices corresponding to grid $i$.

\section{Results and Discussion}

\subsection{Impact of Ecological Service Function and the Intensity of Ecological Demand on the Importance of Ecological Land}

The spatial distribution of important ecological land in the core urban area of Lanzhou is shown in Figure 2. This figure shows that, without considering the intensity of demand for ecological land, the spatial extent of important ecological land in the study area is gradually increasing from the center to the periphery and forming a continuous circular distribution. These important ecological lands are mainly composed of large areas of woodland, grassland, and bare land on the periphery of the study area. In particular, the natural barrier formed by the Qilian Mountains on the southern boundary of the city is the most concentrated and largest area of important ecological land in Lanzhou. However, even 
from the perspective of ecological service capacity, many other very important ecological lands still exist in the urbanized area, such as the scattered urban green space along both banks of the Yellow River, and the wasteland with a low degree of development in the western part of the city. Although these ecological lands that are distributed in urbanized and densely populated areas tend to be relatively small, they still have a high ecological service value; they are irreplaceable in terms of biodiversity maintenance, soil maintenance, and water conservation. Previous studies have shown that the peripheral area of the city is often surrounded by a large area of ecological land; the ecological service capacity of this land will be significantly larger than that of the green space inside the city [38-40]. However, in the core urban area of Lanzhou, the importance of small areas of ecological land such as rivers, lakes, parks, and green spaces inside the urbanized area has not been lessened in the ecological function evaluation. The ecological function of this land should not be ignored.
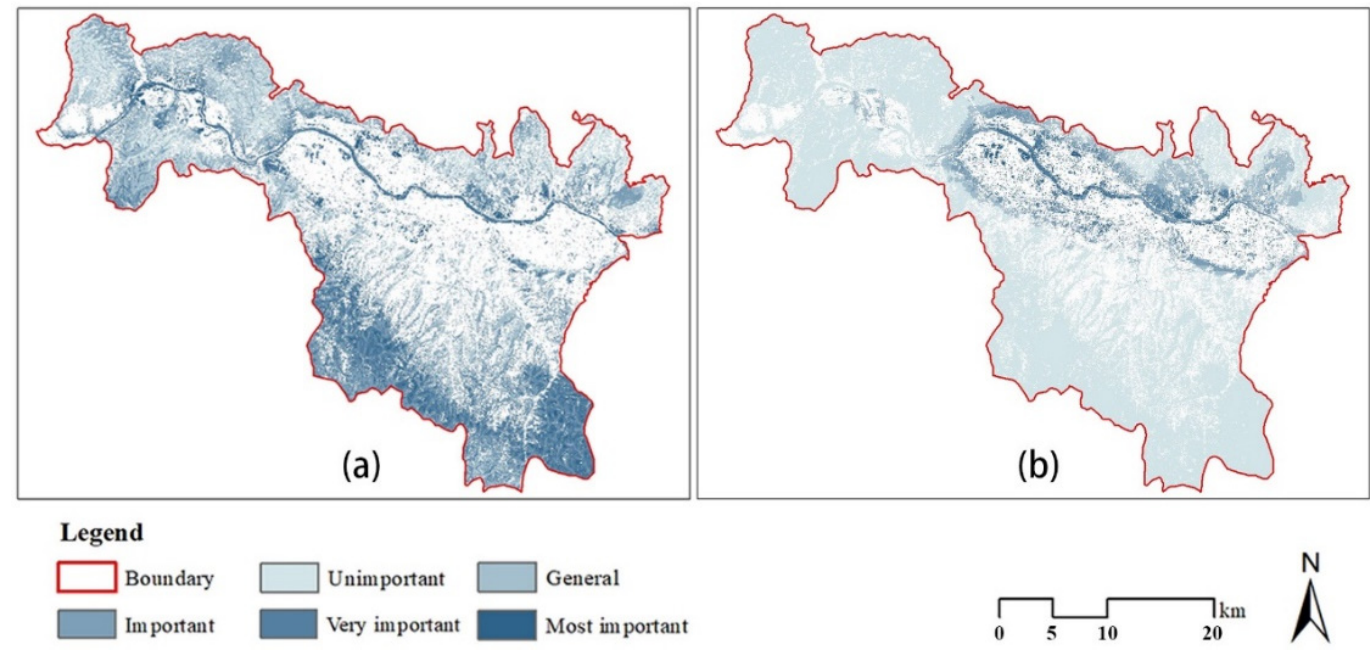

Figure 2. Maps of results of (a) ecological function evaluation and (b) ecological demand intensity evaluation in the study area.

The spatial distribution of ecological land in high demand and in the core urban area of Lanzhou is shown in Figure 2b. This figure shows that, contrary to the distribution of ecological land based on an evaluation of ecological function, the spatial distribution of ecological land based on an evaluation of ecological demand is characterized by gradually increasing importance from the periphery to the city center. The land with the highest ecological demand is concentrated in the urbanized area and surrounding areas, because this land is close to residential areas. Therefore, it can provide urgently needed ecological services for the dense population within an area of construction land. The layout of Lanzhou is affected by the topography of mountain ranges to the north and south. As a result, the construction land of Lanzhou has been expanding in the form of a strip, which also makes the land that is in high demand for ecological needs around the construction land show characteristics of being distributed in long and narrow strips in an east-west direction. Compared with a consideration only of ecological function, an evaluation based on ecological demand intensity highlights the ecological benefits and values of urban park green space and public green space in densely populated areas, such as Lanshan Scenic Resort, Baita Mountain Park, Xujiashan National Forest Park, Wuyishan Ecological Scenic Spot, Yintan Wetland Park, Lanzhou Botanical Garden, and Anning Peach Garden. In addition, in the evaluation of ecological function, the entire section of the Yellow River passing through the city provides some very important ecological land (Figure 2a). However, in the evaluation of the intensity of ecological demand (Figure $2 b$ ), the river section from Chaijiatai in Xigu District to Qingbaishi in Chengguan District was obviously relatively important ecological land, while most of the river sections flowing through Xigu District 
were less important. This is also true because the former has more intense ecological demand and can provide ecosystem services for larger numbers of urban residents. Therefore, more attention should be paid to the ecological benefits of the river and its banks than to the development and potential use of the reach of the Yellow River in this area of high population density.

In brief, after adding the analysis of the intensity of ecological demand, the results were more in line with the actual situation of ecological protection and high-quality development in highly populated and urbanized areas. Figure 3 shows the results of this type of analysis, which includes ecosystem services and ecological demand. However, it is worth considering that, even without an analysis of the intensity of ecological demand, the ecological land within the urbanized area itself has a high ecosystem service value. This seems to be a major feature of cities in the arid areas of northwest China, unlike cities in the coastal areas of southeast China. Generally speaking, the combination of ecological protection and urban development often involves contradictory trade-offs. Urban sprawl will disturb natural ecosystems, turning a large area of green space into hard impervious surfaces, and destroy the circulation of natural material and energy [41-45]. However, it seems that the relationship between development and environmental protection needs to be reexamined in the arid hilly areas of northwest China. The cold climate and limited rainfall result in natural low biodiversity with limited green space in the arid hilly areas of northwest China. The ravines and deep valleys greatly weaken the ecological value of the non-urbanized areas. Some urban parks and public green spaces in the urbanized areas are adequately funded and maintained, which has significantly improved the ecological benefits they provide; they may even provide the most important natural services and ecological support for some cities. Therefore, urban sprawl may not necessarily be the cause of ecological damage for cities in arid hilly areas of northwest China; in contrast, urbanization may provide opportunities for ecological restoration and improvement. Of course, the premise requires land managers to pay attention to the planning for and management of existing ecological land [46], as well as managing the integrity of the overall ecological spatial pattern of the city.

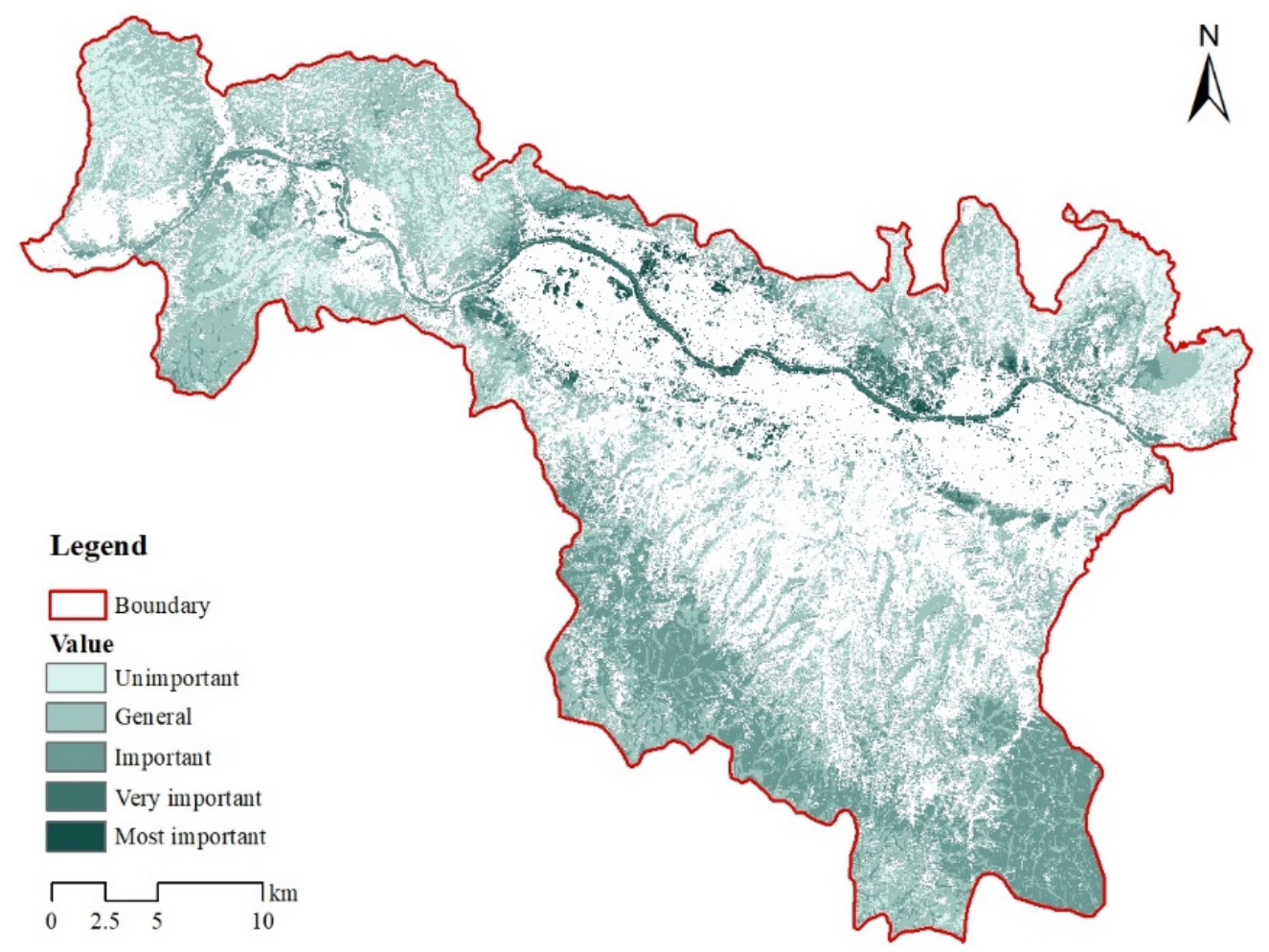

Figure 3. Comprehensive evaluation results for ecological land importance in the study area. 


\subsection{Analysis of the Overall Characteristics of Ecological Land Structure}

The results are shown in Table 2. The most important ecological patches covered $12.70 \mathrm{~km}^{2}(1.50 \%$ of the total ecological land, and $1.21 \%$ of the entire study area). The very important ecological patches covered $36.82 \mathrm{~km}^{2}(4.36 \%$ and $3.52 \%$, respectively, as described above). The important ecological patches covered $154.7 \mathrm{~km}^{2}(18.31 \%$ and $14.80 \%$, respectively). The generally important ecological patches covered $401.7 \mathrm{~km}^{2}(47.52 \%$ and $38.40 \%$, respectively). The unimportant ecological patches covered $239.3 \mathrm{~km}^{2}(28.31 \%$ and $22.88 \%$, respectively). Among them, the generally important ecological patches occupied the largest proportion, followed by the unimportant ecological patches, while the important ecological patches were the third largest area. Meanwhile, the most important and very important ecological patches covered the smallest areas of both total ecological land and the entire study area. That is, high value ecological land in the core urban area of Lanzhou is still very scarce; almost all the most important and very important ecological patches were in urbanized areas (Figure 4). Meanwhile, the large amount of ecological land outside the urbanized area was of relatively low value. This finding shows that the ecological land within an urbanized setting provides many much-needed ecological benefits. In addition, away from urbanized areas the ecological land has a low amount of green space, with rather poor-quality land; here, the ecological services of maintaining biodiversity and conserving soil and water are still weak. It is not possible to provide the higher quality ecological land typical of the urbanized area in nearby rural areas without major changes. The above problems are not only caused by the limitations of climate, terrain, and other natural conditions. Slow urban expansion has included positive steps toward environmental transformation and improvement in Lanzhou in recent years; nevertheless, these positive effects in the city itself have failed to radiate and drive the optimization of environmental conditions in the peripheral areas of the city.

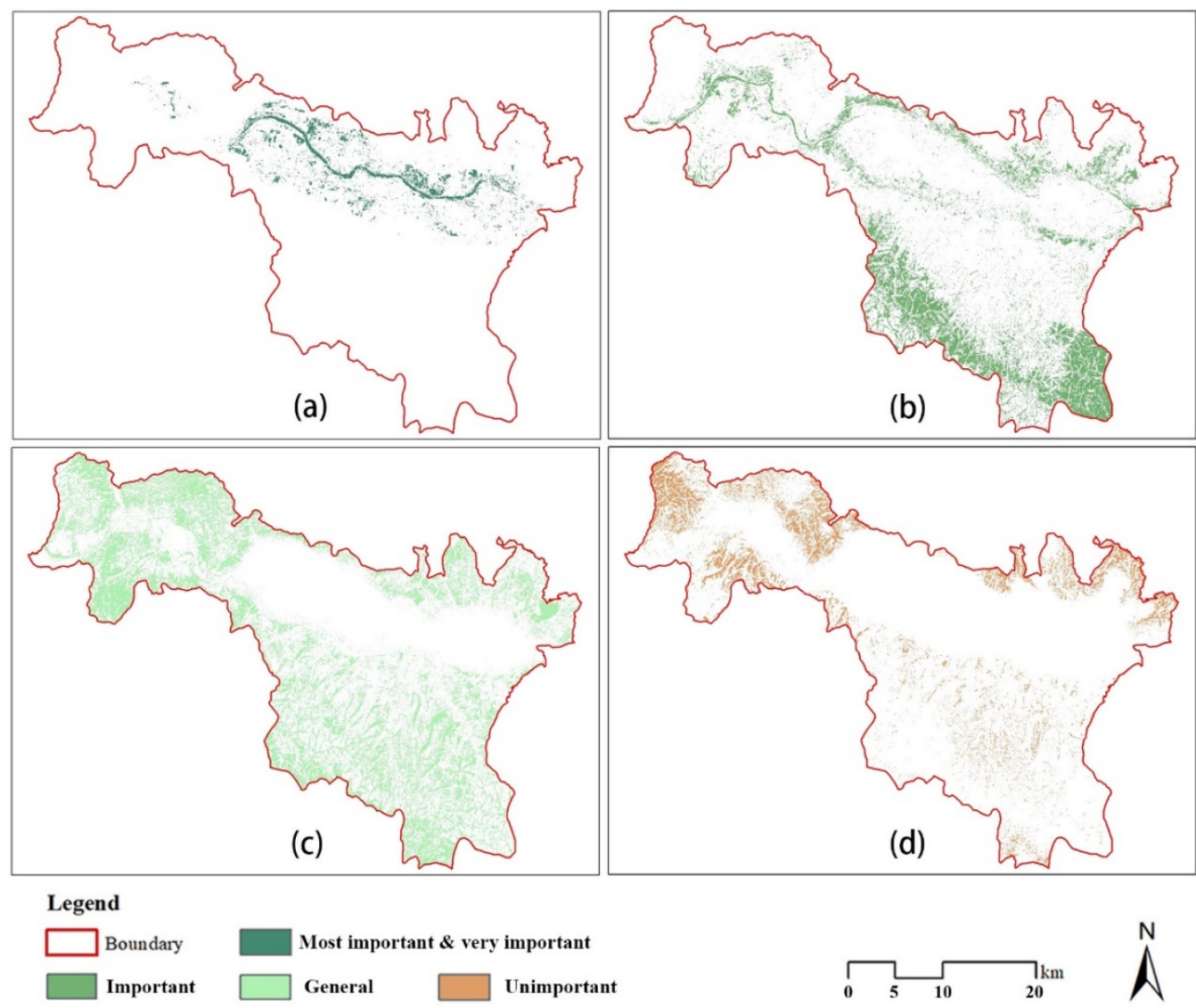

Figure 4. Distribution of: (a) the most important and very important, (b) important, (c) generally important, and (d) unimportant ecological land. 
Table 2. Area and proportion of ecological land at different importance levels.

\begin{tabular}{cccc}
\hline Importance Level of Ecological Patches & Coverage Area $\mathbf{( k m}^{\mathbf{2})}$ & $\begin{array}{c}\text { Proportion in All } \\
\text { Ecological Land (\%) }\end{array}$ & $\begin{array}{c}\text { Proportion in the Study } \\
\text { Area (\%) }\end{array}$ \\
\hline The most important ecological patches & 12.70 & 1.5 & 1.21 \\
The very important ecological patches & 36.82 & 4.36 & 3.52 \\
The important ecological patches & 154.7 & 18.31 & 14.8 \\
The generally important ecological patches & 401.7 & 47.52 & 38.4 \\
The unimportant ecological patches & 239.3 & 28.31 & 22.88 \\
\hline
\end{tabular}

Note: The proportion of non-ecological land in the study area is $19.19 \%$.

Although the most and very important ecological patches in the urbanized area cover small, fragmented areas, this rare core urban area of Lanzhou can provide high-quality ecosystem services for urban residents. These areas should be treasured, and construction should be strictly prohibited. Land management in these areas should emphasize their ecological importance. These lands can not only beautify the living environment but also meet the daily outdoor leisure needs of urban residents. Therefore, future urban planning and land management should focus on promoting the improvement and positive environmental development of the large areas of ecological land surround the urbanized areas of this region; in addition, attention should also be paid to the protection of the core ecological space inside the city.

\subsection{Analysis of Ecological Land Structure Characteristics at the Land Use Level}

Figure 5 shows the distribution of the five types of ecological land in the study area. Most woodlands serve as important ecological land with important ecological patches accounting for $68.72 \%$ of the total area of woodland, while the unimportant and most important ecological patches only accounted for $0.57 \%$ and $0.45 \%$ of the total area of woodland, respectively. Woodlands in the study area typically have a high level of vegetation coverage, with a strong capacity to provide ecological services. However, most of the woodlands occur in hilly areas with deep valleys, high mountains, and frequent gullies outside the urbanized area. As a result, the relatively barren soil and steep slopes also affect the ability of humans to terraform the landscape and improve the ecological value of woodlands, to a certain extent. Nevertheless, woodland is still a land type with high ecological value in the core area of urban Lanzhou. Woodlands can serve as wind breaks and help fix blowing sand, conserve water, and help to maintain biodiversity, making them irreplaceable and in need of protection. The ecological importance of grassland and bare land is at the generally important level, with generally important ecological patches making up $56.64 \%$ and $54.30 \%$, respectively, of their respective overall landscapes. The proportion of important ecological patches was $22.23 \%$ and $17.19 \%$ for these respective land types. Obviously, a considerable amount of room is available for the improvement of grassland and bare land in terms of ecological value. In the process of urbanization and land management, gradually increasing the vegetation cover in grassland and bare land will undoubtedly greatly enhance the ecological service capacity of these areas allowing them to serve complex functions. Large areas of wasteland and bare land with generally important ecological value can be transformed into urban green public space with high ecological value. 


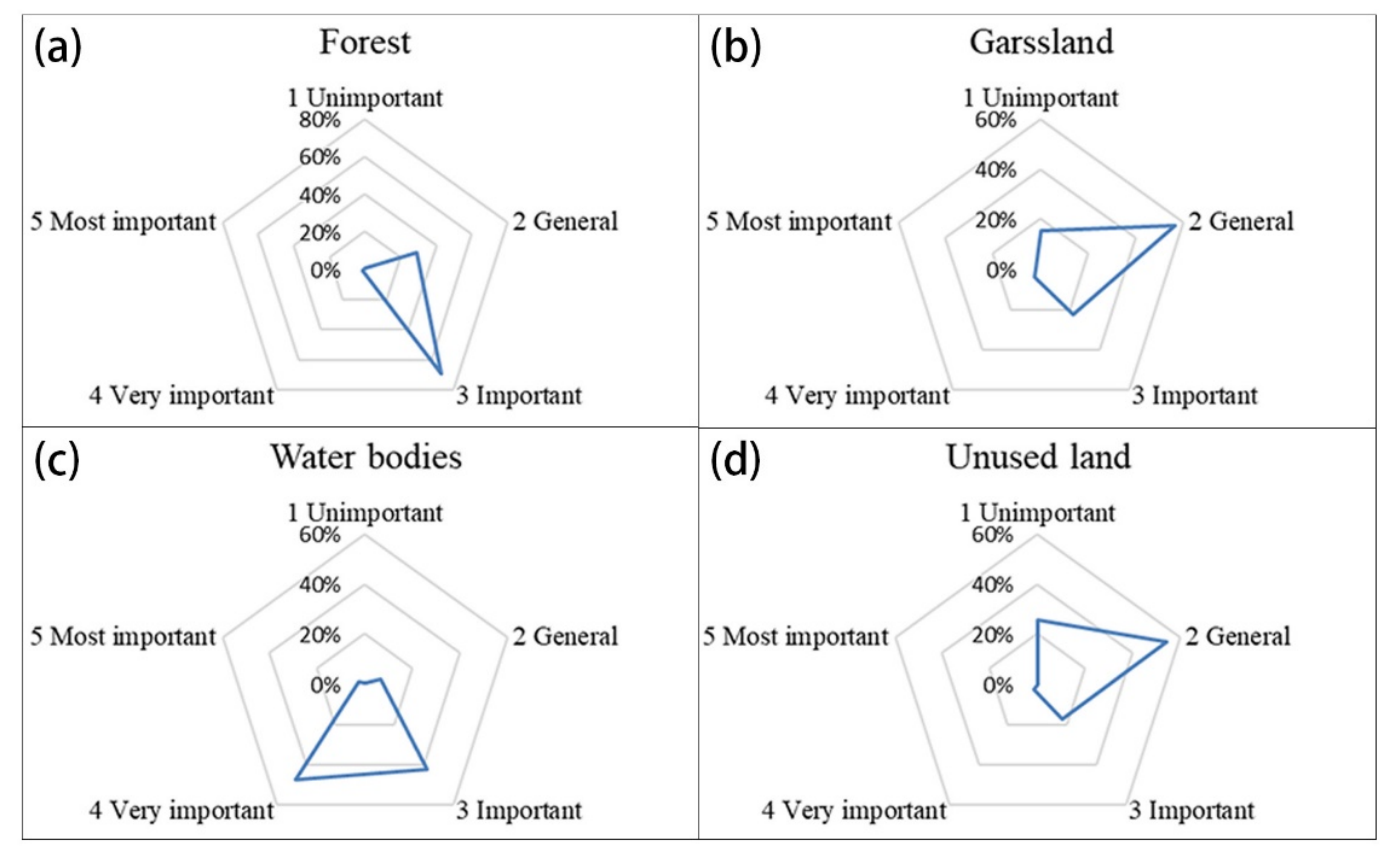

Figure 5. Distribution of ecological land by classification (unimportant to most important) and land type: (a) forest; (b) grassland; (c) water body; (d) unused land.

Water area has the highest average ecological value of ecological land types in the core urban area of Lanzhou. The very important and important ecological patches of water accounted for $47.56 \%$ and $42.38 \%$, of the total water area, respectively. The Yellow River not only provides important ecosystem services for Lanzhou but also serves as a cultural symbol of the city. Therefore, city managers should prioritize the ecological protection of the Yellow River and its surrounding space. Therefore, the ecological transformation and improvement of the Yellow River flood discharge channels in the core urban area of Lanzhou should be strengthened, which is conducive to the formation of a beautiful urban water network system that provides ecological and recreational benefits for city residents.

Figure 6, which illustrates the proportions of various importance levels of the five ecological land types, shows that more than $40 \%$ of the grassland was classified as unimportant, generally important, important, and very important ecological land. In contrast, the proportion of grassland in the most important category is as high as $88.23 \%$. Obviously, grassland makes up the highest proportion in all five types of ecological land. Therefore, from another perspective, grassland has most ecological potential in the core urban area of Lanzhou. In fact, Gansu Province, as one of the six major pastoral areas in China, has a total grassland area of about 14.17 million ha. The structural proportions of various ecological land types in the core urban area of Lanzhou reflect in miniature the distribution of land resources in Gansu Province, where grassland undoubtedly plays an important ecological barrier function across the landscapes of the province. In addition to ecological functions, the open and rolling grassland has a unique northwest-China charm in visual perception and provides excellent aesthetic value; many landscape perception studies have also pointed out that sparse forest and grassland, also known as savannahs, is the most popular landscape type among humans [47,48]. In addition, small ecological patches of grassland can effectively enhance the biodiversity of grass and other flowering plants [49], while large areas of grass and flowering plants can also form an effective ecological interface and provide sparse landscape nodes in a city, which is of great significance for wind and sand fixation, along with improving the urban landscape. However, the grassland in the core urban area of Lanzhou has not been fully given adequate attention. This is especially true for the wasteland areas outside urbanized Lanzhou, which suffer from a lack of planning and management meaning they face the risk of further ecological deterioration at any time. Therefore, city managers should strengthen the use and reestablishment of 
urban grassland, and bring into full play the ecological, social, and economic benefits of grassland during the development of urban land.

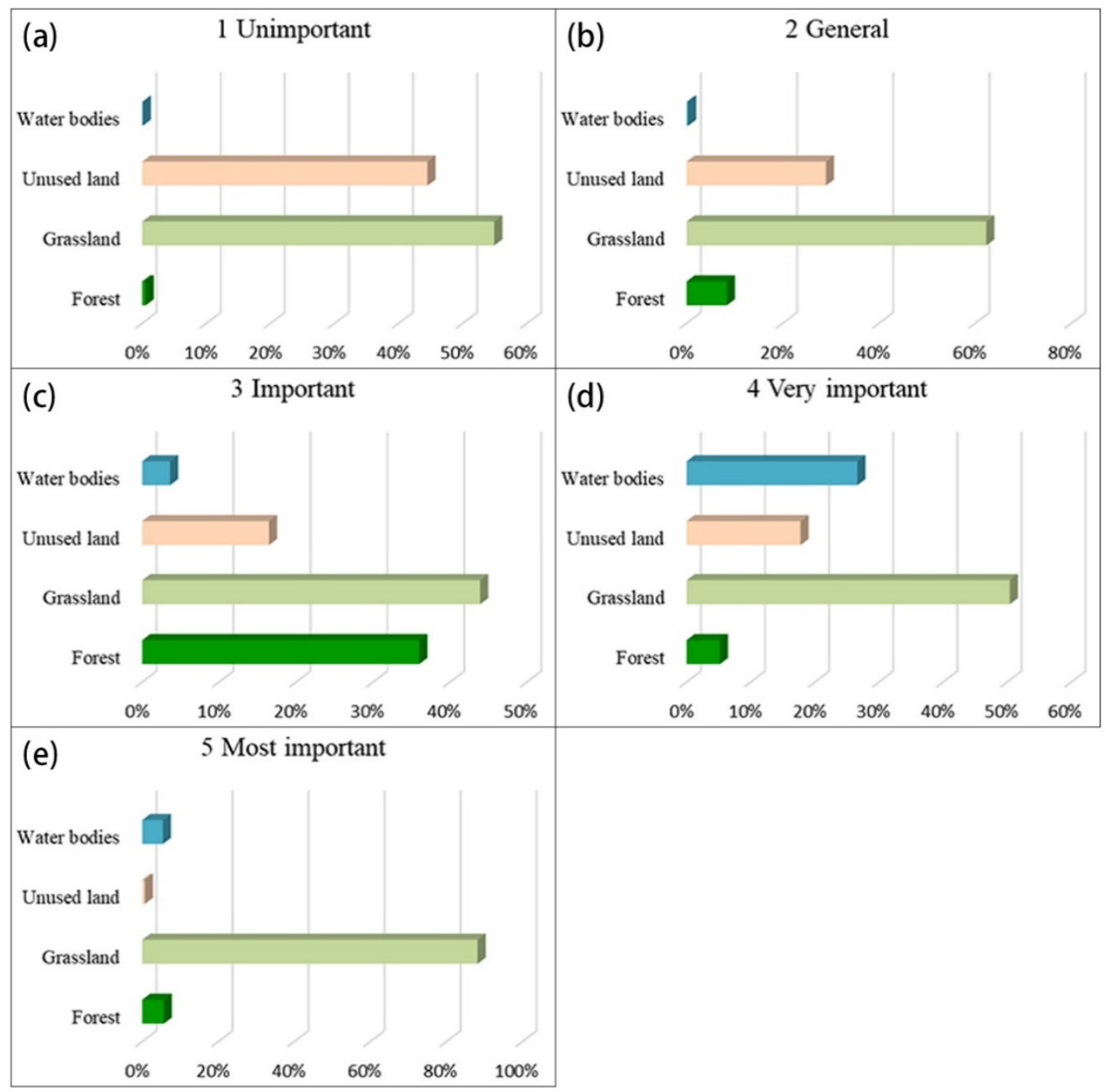

Figure 6. Percentages of the five types of ecological land as a proportion of all ecological land types within each level: (a) unimportant; (b) generally important; (c) important; (d) very important; (e) most important.

\subsection{Analysis of the Structural Characteristics of Ecological Land at the Level of Spatial Distribution}

Figure 7 shows the spatial distribution of the five importance levels of ecological land in Lanzhou. From the perspective of distribution and orientation (Figure 7a), ecological land of different importance levels presents significant anisotropic distribution characteristics. Among them, the districts of Chengguan and Anning had the smallest amount of ecological land, while Qilihe and Xigu districts had the most. The most important and very important ecological lands are mainly concentrated in the central and northern part of the study area, which are along the banks of the Yellow River and in the densely populated areas of Chengguan, Qilihe, and Anning. Most of the important ecological land is concentrated in the southern and southeastern parts of the study area, namely in the southern mountainous area of Qilihe. This area of the Qilian Mountains includes protected natural areas such as Xinglongshan and Shifogou national forest parks that lie in the continuous mountainous areas that have relatively rich plant resources. Good vegetation combined with natural topography forms a unique mountain ecological barrier. Generally important ecological lands are mainly distributed in the northwestern and southeastern parts of the research area, from the point of view of administrative divisions. Similarly, Qilihe and Xigu have 
a large number of generally important ecological lands, while Chengguan and Anning districts have a relatively small number of these lands. This has occurred because the administrative areas of Qilihe and Xigu districts are larger than those of Chengguan and Anning. However, due to the relatively high proportion of urbanized land in Chengguan and Anning, the proportion of ecological land has been reduced to some extent. As a result, these districts have only a small number of generally important ecological land units. When reviewing the structural characteristics analysis of land types in each administrative region (Figure $7 \mathrm{~b}$ ), one can see that the generally important grade of ecological land in Qilihe District mainly consisted of the forest and grassland with relative steep slopes, while the generally important ecological land in Xigu District was mainly composed of barren grassland and undeveloped bare land. Therefore, from the perspective of land use types, the generally important ecological land in Qilihe District is more suitable for further ecological restoration; that is, based on maintaining the existing forest structure and function, the existing forest and grassland with poor terrain and soil quality could be transformed into high-quality forest land by means of ecological conservation and restoration with the goal of maintaining and improving the regional environment. The generally important grade ecological land in Xigu District, namely the grassland and bare land located in relatively flat areas, is more suitable for transformation into public green space during urbanization, so as to provide convenient recreational opportunities for urban residents in an aesthetically pleasing landscape. In recent years, Lanzhou has adopted the development strategy of "expanding east, west and north while promoting the south", with the goal of addressing the restrictions of geographical conditions to make more land readily accessible. Among these aims, the "promoting the south" and "expanding west" involve Qilihe and Xigu, respectively, especially for the important and generally important ecological land in the region. That is, management of a large number of grassland and bare land areas needs to be addressed and planned so as to protect these areas during the process of urban expansion, so as to form a more perfect green infrastructure space system during the new round of urbanization.

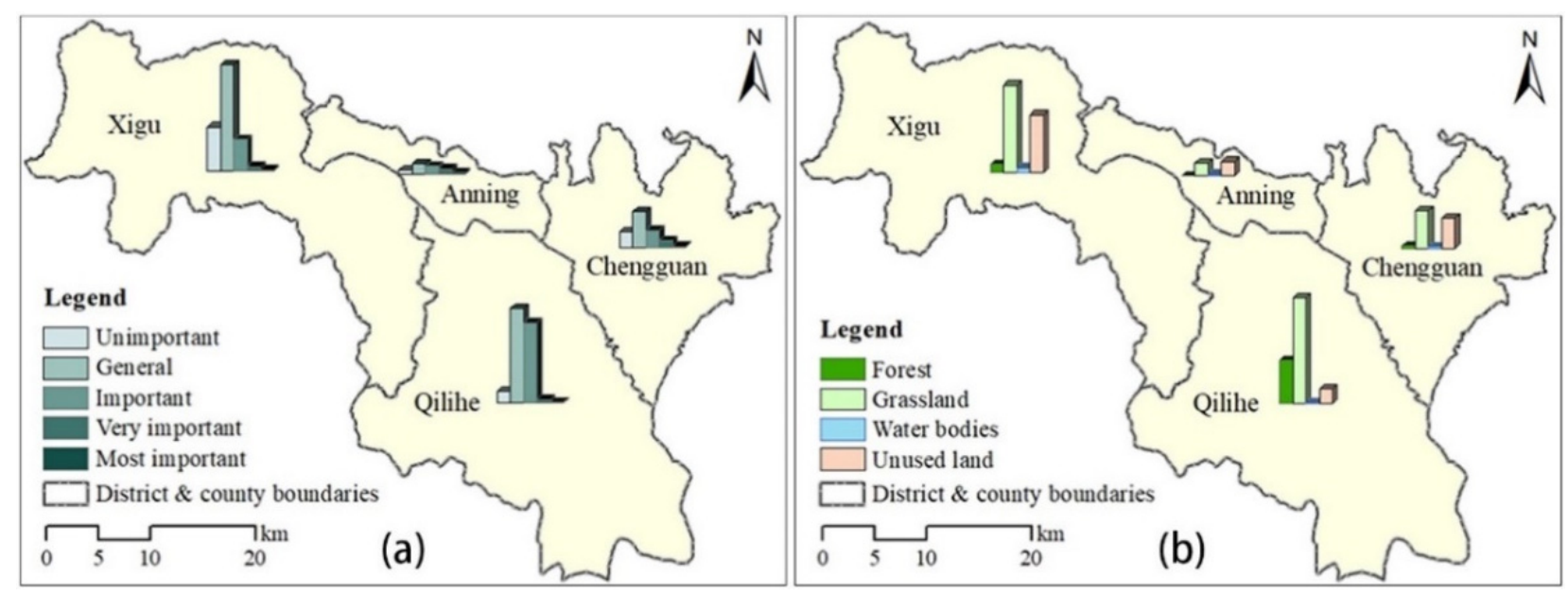

Figure 7. Distribution of various types of ecological land in different regions: (a,b) show the proportions of ecological land with different importance levels and various land types, respectively, in the core urban districts of Lanzhou.

\subsection{Significance and Application}

The importance evaluation of ecological land from the two aspects of ecological function and ecological demand can provide a new perspective for the identification of ecological sources and the construction of ecological patterns [16], especially in high-density urban areas. However, the existing research focuses mainly on the natural value of ecological land [50-52], and less on the importance of ecological land from the perspective of humanistic care. For the arid hilly areas in northwest China, such research is lacking. 
The ecological environment in the arid hilly areas in northwest China is poor, the land is tight, and the contradiction between construction and protection is more acute. Therefore, it is particularly urgent to evaluate the importance of ecological land. Taking this as the starting point, this study makes a corresponding attempt. On the basis of comprehensively considering ecological function and ecological demand, this study mainly has two innovations in its methods: first, according to the regional characteristics of arid hilly areas in northwest China, appropriate ecological function evaluation dimensions and relevant parameters of ecological demand model are selected. Second, the classification and weight of specific indicators are refined through expert scoring and analytic hierarchy process, so as to make the evaluation method more targeted. In addition, this study takes Lanzhou as a case, which can provide reference for ecological restoration and urban design of cities in arid hilly areas in northwest China, and also has a certain practical significance. It should be noted that, although the evaluation system proposed in this study is universal for the evaluation of ecological land in arid hilly areas of northwest China, in specific operation the parameter details in the model can be adjusted appropriately according to the regional characteristics in order to produce more accurate results.

\subsection{Limitations}

This study mainly evaluated the importance of the core urban ecological land in Lanzhou. This was done by coupling the service function of ecological land use and the intensity of ecological demand using a simple evaluation method. The study used scientific method to systematically evaluate the sources of ecological services from different types of land use, emphasizing areas described as ecological land as opposed to urbanized or other land use types. In general, this method mainly involved the investigation of the vertical ecological process of ecological patches, i.e., the vertical superposition effect of various properties inside a certain ecological source. The study lacks a consideration of the overall horizontal ecological processes in the region. In follow-up research, it will be necessary to expand the evaluation dimension of the importance of ecological land, and include the material and information flow capacity between ecological patches into the evaluation system. In addition, Morphological Spatial Pattern Analysis (MSPA) could be used to guide the identification of habitat sources based on spatial-morphological attributes such as patch area and spatial-topological relationships. The application of MSPA in the identification of ecological sources and the construction of a regional ecological security network is becoming mature [53-56]. How to effectively integrate the concepts and methods of MSPA in the evaluation of the importance of ecological land will be the content of future in-depth exploration of this topic.

\section{Conclusions}

This study aims to establish an importance evaluation system for ecological land use, reveal the distribution and development characteristics of urban ecological land in the arid hilly region of northwest China represented by Lanzhou, and provide reference for ecological restoration and urban planning in Lanzhou and other arid inland cities along the upper reaches of the Yellow River. The main conclusions follow.

(1) The model used to evaluate the importance of ecological land was based on the dual perspectives of the function of providing ecosystem services and the intensity of ecological demand. This model is more suitable to evaluate for the need for ecological protection in arid and hilly areas of northwest China and highly urbanized areas. Compared with only considering the ecosystem service function of ecological land, the research results can consider the demands and needs of urban residents and can effectively identify the types of ecological land that have a high degree of ecological demand within the city, which has practical significance for the protection of ecological resources in the core of the city.

(2) For the core urban area of Lanzhou, even from a single perspective of ecological function, urban parks and public green space in densely populated areas of urbanized area 
also have very important ecological values. After adding an evaluation of the intensity of ecological demand, the ecological importance of parks and other green space in urbanized area was further strengthened. Most of the most important ecological land was distributed in densely populated areas. Obviously, for cities in the arid and hilly areas of northwest China represented by the core urban area of Lanzhou, the spread of urbanized areas will not mean that the surrounding natural landscape will inevitably be destroyed. On the contrary, the development of cities may provide opportunities for the ecological restoration and renovation of surrounding barren and bare land.

(3) The most important and very important ecological land in the core area of Lanzhou only accounted for $5.86 \%$ of the total area of all ecological land within the city, indicating that high-value ecological land in the core area of Lanzhou is still very scarce. Among these important areas, the water area (mainly the Yellow River and its waterfront space) is the ecological land with the highest average ecological value in Lanzhou, followed by forest land. In addition, one can see that the land type with the highest spatial proportion among all levels of ecological land is grassland. Grassland can be said to be the ecological land with the most potential in the core urban area of Lanzhou; its ecological function will be continuously lost over time if it is not properly managed and protected. Careful planning and use can allow grassland to serve as an indispensable ecological barrier in Lanzhou, which can not only play an ecological function but can also provide good aesthetic space and recreational opportunities for the general public.

(4) From the perspective of spatial distribution, the urbanized areas of Chengguan and Anning districts accounted for a large proportion; these areas have a limited amount of ecological land, but the most important ecological land is also mostly distributed here. Qilihe and Xigu districts have more generally important graded areas of forest, grassland, and bare land, although the current ecological value of these lands is limited; nevertheless, these lands have great potential for ecological improvement, which should be considered in the future. With the accelerating development of Lanzhou in recent years, a large number of underused ecological lands in Qilihe and Xigu undoubtedly include valuable properties in the core urban area of Lanzhou. These areas will need to be continuously improved to reach their peak ecological service capacity in light of urban sprawl and urban function transfer. Appropriate land management should be carried out to further improve the level of connectivity through the construction of ecological corridors, so as to form a scientific and reasonable regional ecological security pattern and lay a healthy and sustainable material foundation for a new round of urban development.

Author Contributions: Conceptualization, Y.L. and C.L.; methodology, Y.L. and C.L.; formal analysis, Y.L., J.M., J.P., Z.L. and M.H.; investigation, Y.L., C.L., J.M., J.P., Z.L. and M.H.; writing-original draft preparation, Y.L.; writing — review and editing, C.L. All authors have read and agreed to the published version of the manuscript.

Funding: This research was funded by Fundamental Research Funds for the Central Universities (21lzujbkydx010, 2020jbkyjc002).

Institutional Review Board Statement: Not applicable.

Informed Consent Statement: Not applicable.

Data Availability Statement: The data used to support the findings of this study are available from the corresponding author upon reasonable request.

Acknowledgments: We thank LetPub (www.letpub.com (accessed on 16 August 2021)) for its linguistic assistance during the preparation of this manuscript.

Conflicts of Interest: The authors declare no conflict of interest. 


\section{References}

1. $\quad$ Liu, Y.Q.; Wang, R.Y.; Lu, Y.; Li, Z.G.; Chen, H.S.; Cao, M.Q.; Zhang, Y.R.; Song, Y.M. Natural outdoor environment, neighbourhood social cohesion and mental health: Using multilevel structural equation modelling, streetscape and remote-sensing metrics. Urban For. Urban Green. 2020, 48, 126576. [CrossRef]

2. Yu, F.; Li, X.B.; Zhang, L.J.; Xu, W.H.; Fu, R.; Wang, H. Study of ecological land in China: Conception, classification, and spatial-temporal pattern. Acta Ecol. Sin. 2015, 35, 4931-4943.

3. Aminzadeh, B.; Khansefid, M. A case study of urban ecological networks and a sustainable city: Tehran's metropolitan area. Urban Ecosyst. 2010, 13, 23-36. [CrossRef]

4. Vergnes, A.; Kerbiriou, C.; Clergeau, P. Ecological corridors also operate in an urban matrix: A test case with garden shrews. Urban Ecosyst. 2013, 16, 511-525. [CrossRef]

5. Xie, H.; Yao, G.; Liu, G. Spatial evaluation of the ecological importance based on GIS for environmental management: A case study in Xingguo county of China. Ecol. Indic. 2015, 51, 3-12. [CrossRef]

6. Peng, J.; Zong, M.L.; Hu, Y.N.; Liu, Y.X.; Wu, J.S. Assessing landscape ecological risk in a mining city: A case study in Liaoyuan city, China. Sustainability 2015, 7, 8312-8334. [CrossRef]

7. Wu, J.S.; Zhang, L.Q.; Peng, J.; Feng, Z.; Liu, H.M.; He, S.B. The integrated recognition of the source area of the urban ecological security pattern in Shenzhen. Acta Ecol. Sin. 2013, 33, 4125-4133.

8. Peng, J.; Wang, A.; Liu, Z.X.; Ma, J.; Wu, J.S. Research progress and prospect on measuring urban ecological land demand. Acta Georaphica Sin. 2015, 70, 333-346.

9. Zhou, Z.; Meng, J.J.; Qi, Y.; Peng, F.L. Importance of ecological lands and their pattern optimization in China: A review. Chin. J. Ecol. 2016, 35, 218-225.

10. Orban, E.; Sutcliffe, R.; Dragano, N.; Jöckel, K.H.; Moebus, S. Residential surrounding greenness, self-rated health and interrelations with aspects of neighborhood environment and social relations. J. Urban Health 2017, 94, 158-169. [CrossRef]

11. Van Renterghem, T.; Botteldooren, D. View on outdoor vegetation reduces noise annoyance for dwellers near busy roads. Landsc. Urban Plan. 2016, 148, 203-215. [CrossRef]

12. Enssle, F.; Kabisch, N. Urban green spaces for the social interaction, health and well-being of older people: An integrated view of urban ecosystem services and socio-environmental justice. Environ. Sci. Policy 2020, 109, 36-44. [CrossRef]

13. Baró, F.; Palomo, I.; Zulian, G.; Vizcaino, P.; Haase, D.; Gómez-Baggethun, E. Mapping ecosystem service capacity, flow and demand for landscape and urban planning: A case study in the Barcelona metropolitan region. Land Use Policy 2016, 57, 405-417. [CrossRef]

14. Wolff, S.; Schulp, C.J.E.; Verburg, P.H. Mapping ecosystem services demand: A review of current research and future perspectives. Ecol. Indic. 2015, 55, 159-171. [CrossRef]

15. Zhang, Y.N.; Chen, Z.J.; Zhang, Y.Q.; Mei, M.Y. Urban ecological importance assessment based on ecological function and ecological demand: A case study of Changsha. Resour. Environ. Yangtze Basin 2018, 27, 2358-2367.

16. Zhang, L.Q.; Peng, J.; Liu, Y.X.; Wu, J.S. Coupling ecosystem services supply and human ecological demand to identify landscape ecological security pattern: A case study in Beijing-Tianjin-Hebei region, China. Urban Ecosyst. 2017, 20, 701-714. [CrossRef]

17. Zhang, X.C.; Liang, X.C.; Song, X.; Liu, J.S. Spatial pattern of the mismatch degrees of the high-quality development of tourism industry in the Yellow River basin. J. Arid Land Resour. Environ. 2020, 34, 201-208.

18. Wang, S.P.; Qiao, H.F.; Feng, J.; Xie, S.Y. The spatio-temporal evolution of tourism eco-efficiency in the Yellow River basin and its interactive response with tourism economy development level. Econ. Geogr. 2020, 40, 81-89.

19. Ma, L. Debate and thinking about the ecological impact of "bulldoze mountains to build new city": A case study of Lanzhou new city. Mod. Urban Res. 2016, 6, 85-90.

20. Gao, J.X.; Xu, D.L.; Qiao, Q.; Zou, C.X.; Wang, Y.; Tian, M.R.; Wang, Y. Pattern construction of natural ecological space and planning theory exploration. Acta Ecol. Sin. 2020, 40, 749-755.

21. Gozdowski, D.; Stępién, M.; Panek, E.; Varghese, J.; Bodecka, E.; Rozbicki, J.; Samborski, S. Comparison of winter wheat NDVI data derived from Landsat 8 and active optical sensor at field scale. Remote Sens. Appl. 2020, 20, 100409. [CrossRef]

22. Cao, H.Y.; Han, L.; Liu, Z.H.; Li, L.Z. Monitoring and driving force analysis of spatial and temporal change of water area of Hongjiannao Lake from 1973 to 2019. Ecol. Inform. 2021, 61, 101230. [CrossRef]

23. Song, N.Y.; Wei, L. Study on urban greening in Lanzhou from 1941 to 1949. J. Arid Land Resour. Environ. 2019, 33, 184-189.

24. Ma, C.; Li, S.; Liu, J.; Gao, Y.; Wang, Y. Regionalization of ecosystem Services of Beijing-Tianjin-Hebei Area based on SOFM neural network. Prog. Geogr. 2013, 32, 1383-1393.

25. Meng, J.J.; Wang, Y.; Wang, X.D.; Zhou, Z.; Sun, N. Construction of landscape ecological security pattern in Guiyang based on mcr model. Resour. Environ. Yangtze Basin 2016, 25, 1052-1061.

26. Bi, X.L.; Ge, J.P. Evaluating ecosystem service valuation in China based on the IGBP land cover datasets. J. Mt. Sci. 2004, 2, 48-53.

27. Zurlini, G.; Petrosillo, I.; Aretano, R.; Castorini, I.; Zaccarelli, N. Key fundamental aspects for mapping and assessing ecosystem services: Predictability of ecosystem service providers at scales from local to global. Ann. Bot. 2014, 4, 53-63.

28. Jahun, B.G.; Ibrahim, R.; Dlamini, N.S.; Musa, S.M. Review of soil erosion assessment using RUSLE model and GIS. J. Biol. Agric. Healthc. 2015, 5, 36-47.

29. Van Oost, K.; Govers, G.; Desmet, P. Evaluating the effects of changes in landscape structure on soil erosion by water and tillage. Landsc. Ecol. 2000, 15, 577-589. [CrossRef] 
30. Liu, B.Y.; Nearing, M.A.; Risse, L.M. Slope gradient effects on soil lossfor steep slopes. Trans. ASAE 1994, 37, 1835-1840. [CrossRef]

31. Wischmeier, W.H.; Smith, D.D. Predicting rainfall erosion losses: Aguide to conservation planning with the universal soil loss equation. In Agricultural Handbook No. 537; United States Department of Agriculture: Springfield, IL, USA, 1978.

32. Wischmeier, W.H.; Smith, D.D. Rainfall energy and its relationship tosoil loss. Trans. Am. Geophys. Union 1958, 39, $285-291$. [CrossRef]

33. Hu, G.; Song, H.; Shi, X.J.; Zhang, M.L.; Liu, X.J.; Zhang, X.L. Soil erosion characteristics based on RUSLE in the Wohushan reservoir watershed. Sci. Geogr. Sin. 2018, 38, 610-617.

34. Gong, S.H.; Xiao, Y.; Zheng, H.; Xiao, Y.; Ouyang, Z.Y. Spatial patterns of ecosystem water conservation in China and its impact factors analysis. Acta Ecol. Sin. 2017, 37, 2455-2462.

35. Luo, X.; Yang, J.; Sun, W.; He, B.J. Suitability of human settlements in mountainous areas from the perspective of ventilation: A case study of the main urban area of Chongqing. J. Clean. Prod. 2021, 310, 127467. [CrossRef]

36. Chen, S.L.; Chen, H.H.; Li, X. The ability of nighttime imagery in monitoring economic activity in different scales. Sci. Geogr. Sin. 2020, 40, 1476-1483.

37. Lv, Q.; Liu, H.B. Multiscale spatio-temporal characteristics of carbon emission of energy consumption in Yellow River basin based on the nighttime light datasets. Econ. Geogr. 2020, 40, 12-21.

38. Terrado, M.; Sabater, S.; Chaplin-Kramer, B.; Mandle, L.; Ziv, G.; Acuña, V. Model development for the assessment of terrestrial and aquatic habitat quality in conservation planning. Sci. Total Environ. 2015, 540, 63-70. [CrossRef]

39. Wang, L.R.; Feng, X.L.; Chang, Q.; Liu, H.; Wang, J. Pattern construction of habitat network for urban green space based on the compound model of InVEST and MCR. Chin. Landsc. Archit. 2020, 36, 113-118.

40. Han, Y.W.; Li, Y.N.; Li, F.Z. Effects of Landscape Patterns of Urban Green Spaces on “Core Habitat” Quality. Landsc. Archit. 2020, 27, 83-87.

41. Fan, H.Y.; Yu, Z.W.; Yang, G.Y.; Liu, T.Y.; Hung, C.H.; Vejre, H. How to cool hot-humid (Asian) cities with urban trees? An optimal landscape size perspective. Agric. For. Meteorol. 2019, 265, 338-348. [CrossRef]

42. Yang, G.Y.; Yu, Z.W.; Jørgensen, G.; Vejre, H. How can urban blue-green space be planned for climate adaption in high-latitude cities? A seasonal perspective. Sustain. Cities Soc. 2020, 53, 101932. [CrossRef]

43. Yang, J.; Wang, Y.C.; Xue, B.; Li, Y.F.; Xiao, X.M.; Xia, J.H.; He, B.J. Contribution of urban ventilation to the thermal environment and urban energy demand: Different climate background perspectives. Sci. Total Environ. 2021, 795, 148791. [CrossRef]

44. Sun, R.; Wang, Y.; Chen, L. A distributed model for quantifying temporal-spatial patterns of anthropogenic heat based on energy consumption. J. Clean. Prod. 2018, 170, 601-609. [CrossRef]

45. Ebrahimi, A.; Motamedvaziri, B.; Nazemosadat, S.M.J.; Ahmadi, H. Investigating the land surface temperature reaction to the land cover patterns during three decades using landsat data. Int. J. Environ. Sci. Technol. 2021. [CrossRef]

46. Yang, J.; Yang, R.X.; Chen, M.H.; Su, C.H.; Zhi, Y.; Xi, J.C. Effects of rural revitalization on rural tourism. J. Hosp. Tour. Manag. 2021, 47, 35-45. [CrossRef]

47. Lis, A.; Iwankowski, P. Why is dense vegetation in city parks unpopular? The mediative role of sense of privacy and safety. Urban For. Urban Green. 2021, 59, 126988. [CrossRef]

48. Wartmann, F.M.; Frick, J.; Kienast, F.; Hunziker, M. Factors influencing visual landscape quality perceived by the public: Results from a national survey. Landsc. Urban Plan. 2021, 208, 104024. [CrossRef]

49. Vega, K.A.; Kueffer, C. Promoting wildflower biodiversity in dense and green cities: The important role of small vegetation patches. Urban For. Urban Green. 2021, 62, 127165. [CrossRef]

50. He, J.H.; Huang, J.L.; Li, C. The evaluation for the impact of land use change on habitat quality: A joint contribution of cellular automata scenario simulation and habitat quality assessment model. Ecol. Model. 2017, 366, 58-67. [CrossRef]

51. Zhang, M.D.; Zhang, F.; Li, X. Evaluation of Habitat Quality Based on InVEST Model: A Case Study of Tongzhou District of Beijing, China. Landsc. Archit. 2020, 27, 95-99.

52. Wu, M.Q.; Hu, M.M.; Wang, T.; Fan, C.; Xia, B.C. Recognition of urban ecological source area based on ecological security pattern and multi-scale landscape connectivity. Acta Ecol. Sin. 2019, 39, 4720-4731.

53. Wang, Y.; Lin, Q. The Transformation of planning ideas and the exploration of planning methods of urban green space ecological network based on MSPA. Chin. Landsc. Archit. 2017, 33, 68-73.

54. Xie, Y.S.; Wang, Q.N.; Luo, Y.Y. City-level urban green infrastructure evaluation index system based on MSPA: A case study of major cities in Sichuan province. Chin. Landsc. Archit. 2020, 36, 87-92.

55. Chen, H.Y.; Li, X. Optimization of green space habitat network of central Beijing based on MSPA-InVEST model. Landsc. Archit. 2021, 28, 16-21.

56. Chen, W.Q.; Tao, Y.; Wu, W.; Ou, W.X. Priority evaluation of ecological protect areas based on MSPA, landscape connectivity, and spatial syntax methods in the Su-Xi-Chang Region. Acta Ecol. Sin. 2020, 40, 289-298. 